\title{
Simulation and Experiment study of ball defects of a two rotors-ball bearing-gear coupling system
}

\author{
Lu Xin ${ }^{1}$, Zhang Junhong ${ }^{1}$, Dai Huwei ${ }^{1}$, Ma Liang ${ }^{2}$ and Wang Jun ${ }^{2}$ \\ ${ }^{1}$ State Key Laboratory of Engine, Tianjin University, 300072 Tianjin, China; \\ ${ }^{2}$ Ren'ai College, Tianjin University, 301636 Tianjin, China
}

\begin{abstract}
A model of a two rotors-ball bearing-gear coupling systems which considering ball defects on bearing was established. In this model the meshing force of gear coupling and ball defects on bearing was considered. A test facility was constructed to verify the simulation results. After simulation and experiment, it was found that there are sideband frequencies beside VC frequency and its multiple frequencies can be found in the faulted rotor system in the spectrum. From the acceleration signal of experiment, it was found the signal of the bearing fault performs as impacts in the high frequency range without any patterns. The characteristics of ball defects of bearing on a two rotors-ball bearing-gear coupling systems were analyzed. It can help analyze the stability of the system and the fault characteristic of ball bearing.
\end{abstract}

\section{Introduction}

Rolling Bearings are widely used in rotating machinery as important supporting component. The failure of bearings may lead to failure of the entire machinery [1]. Depending on research, bearing faults comprise $41 \%$ of failures in induction motor[2].Bearing defects are common faults of rotor-bearing systems including offsized rolling elements, waviness of contacting surfaces, and those developed during operations such as cracks and pits [1].

Various numerical models have been developed to study the dynamic characteristics of rotor [3]-[9], many researches are focused with different on ball bearing faults. Changqing developed a bearing model considering the effects of distributed off-size rolling elements and waviness [5]. Kankar [1] focused on the accurate performance prediction due to the localized defects of micro level on the bearing components. McFadden and Smith [5] extended a single point defect model to a multiple points defects model in order to investigate the effects of bearing geometry, speed, load distribution, transfer function and the decay of vibration. Lynagh [8] presents a detailed model of bearing vibration, including the effect of contact spring non-linearity in balls-toraceways' contacts. Eren [9] analyzed stator via wavelet packet decomposition to detect bearing defects. The proposed method enables the analysis of frequency bands that can accommodate the rotational speed dependence of the bearing defect frequencies.

In this paper, a two-rotor-bearing-gear coupling system model with ball defects on ball bearing was established to study the characteristics of ball defects of ball bearing. A test facility was built to verify the simulation results.

\section{Model of Simulation}

\subsection{Ball bearing model of ball defects}

Based on the study of Kankar [1], the model of inner race defect on the ball bearing is established in this section. The defects on the ball of ball bearing are shown in Figure 1. When the defects of ball contact with inner ring or out ring, the additional clearance $\mu_{b}$ can be written as:

$$
\mu_{b}=\frac{D_{w}-\sqrt{D_{w}^{2}-b_{r}^{2}}}{2}
$$

The triggering condition of the ball defects contact with inner ring and out ring can be written as:

$$
\left\{\begin{array}{l}
-\beta \leq \bmod \left(\frac{\theta_{b}}{2 \pi}\right) \leq \beta(\text { inner }) \\
\pi-\beta \leq \bmod \left(\frac{\theta_{b}}{2 \pi}\right) \leq \pi+\beta(\text { out })
\end{array}\right.
$$

where $\beta=\arcsin \left(\frac{b_{r}}{D_{w}}\right)$

The displacement of ball can be given by:

$$
\delta_{j b}=\delta_{j}-\mu_{b}=\delta \cdot \cos j \varphi-\mu-\mu_{b}
$$

where $\mu$ is the radial clearance of ball bearing, $\delta_{j}$ is the deformation of bearing, $b_{r}$ is the diameter of the ball; $D_{w}$ is the pitch diameter of the bearing. 


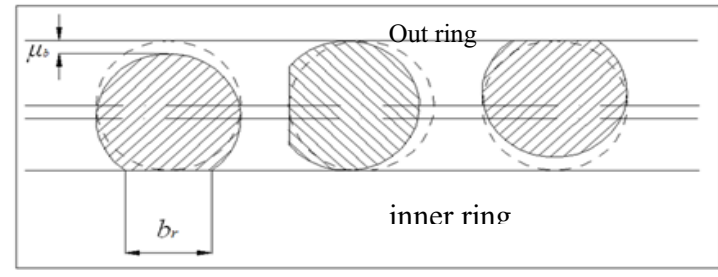

Figure 1. The ball defect of the bearing

According to the Hertzian contact theory, the local Hertzian contact force and deflection relationship for ball bearing can be written as:

$$
F_{b}=k\left(\delta_{j b}\right)^{3 / 2}
$$

where $k$ is constant for Hertzian contact elastic deformation.

\subsection{Gear coupling}

In the gear coupling, the meshing in the male and female couplings is asymmetric (as showed in Fig. 2), gear teeth of the two half-couplings mesh tightly in the right parts and loosely in the left parts. Consequently, the meshing distance of every tooth is changing. According to the research of Zhao [10], the meshing force in the gear coupling consist of two parts: (a) the meshing force caused by torque and (b) the meshing force caused by vibration.

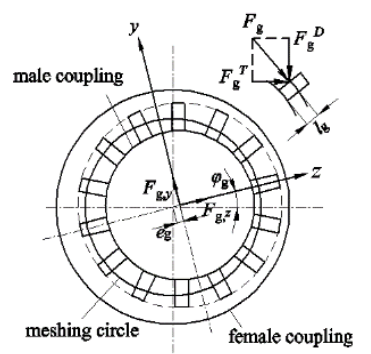

Figure. 2. Schematic diagram of the gear coupling.

\subsubsection{Meshing force caused by torque.}

When gear teeth are meshing tightly to transmit a large torque, deformation of a gear tooth is inevitable and the following meshing force is related to the deformation amount, meshing distance and meshing rigidity. From the study of ref [9], the torque-induced meshing force is given by

$$
F_{\mathrm{g}}^{T}=\phi_{\mathrm{g}} l_{\mathrm{g}} k_{\mathrm{g}}
$$

where $F_{g}^{T}$ is the meshing force due to torque, $\phi_{\mathrm{g}}$ is the deformation angle of gear tooth, $l_{g}$ is the equivalent meshing distance of gear tooth, and $\mathrm{k}_{g}$ is the meshing rigidity of gear tooth. The $\phi_{g}$ of all gear teeth are the same when the coupling is driven by a static torque.

\subsubsection{Meshing force caused by vibration.}

when torque is transmitting by gear teeth, a relative movement between the two meshing teeth takes place induced by the system vibration at the same time. As a result, the displacement of meshing nodes causes a deformation of each tooth so that another meshing force is produced and expressed as

$$
F_{\mathrm{g}}^{D}=e_{\mathrm{g}} k_{\mathrm{g}} \sin \varphi_{\mathrm{g}}
$$

where $F_{g}^{T}$ is the meshing force caused by vibration, $\varphi_{g}$ is the position angle of gear tooth, and $\mathrm{e}_{g}$ is the misalignment of gear coupling.

If there is no torque to transmit, the meshing force will be zero regardless of the vibration displacement, and the meshing force will not be negative. Accordingly, the total meshing force of the $i$ th tooth can be obtained

$$
F_{\mathrm{g}, i}= \begin{cases}\left(\phi_{\mathrm{g}, i} l_{\mathrm{g}, i}+e_{\mathrm{g}} \sin \varphi_{\mathrm{g}, i}\right) k_{\mathrm{g}, i}, & \phi_{\mathrm{g}, i} l_{\mathrm{g}, i}+e_{\mathrm{g}} \sin \varphi_{\mathrm{g}, i}>0 \\ 0, & \phi_{\mathrm{g}, i} l_{\mathrm{g}, i}+e_{\mathrm{g}} \sin \varphi_{\mathrm{g}, i} \leq 0\end{cases}
$$

Then, the reactions of meshing force in the y-axis and $\mathrm{z}$-axis directions of the rotor system are as follows:

$$
\left\{\begin{array}{l}
F_{\mathrm{g}, y}=\sum_{i=1}^{n}\left(\phi_{\mathrm{g}, i} l_{\mathrm{g}, i}+e_{\mathrm{g}} \sin \varphi_{\mathrm{g}, i}\right) k_{\mathrm{g}, i} \sin \theta \\
F_{\mathrm{g}, z}=\sum_{i=1}^{n}\left(\phi_{\mathrm{g}, i} l_{\mathrm{g}, i}+e_{\mathrm{g}} \sin \varphi_{\mathrm{g}, i}\right) k_{\mathrm{g}, i} \cos \theta
\end{array}\right.
$$

\subsection{Model of rotor}

The rotor system studied in this paper (shown in Fig. 3 ) conducts of two shafts, two disks, three ball bearings, a SFD, and a gear coupling. Each shaft has a disk on it, and the two shafts are connected by the gear coupling. The rotor is supported in the " $0-2-1$ " form which means no bearing is mounted in front of the left disk, two bearings are mounted in the middle of the two disks, and one bearing mounted behind the right disk. The two bearings in the middle are both located on the left shaft. In this paper, Bearing 1 was assumed to the defects bearing. The equations of Model can be written as:

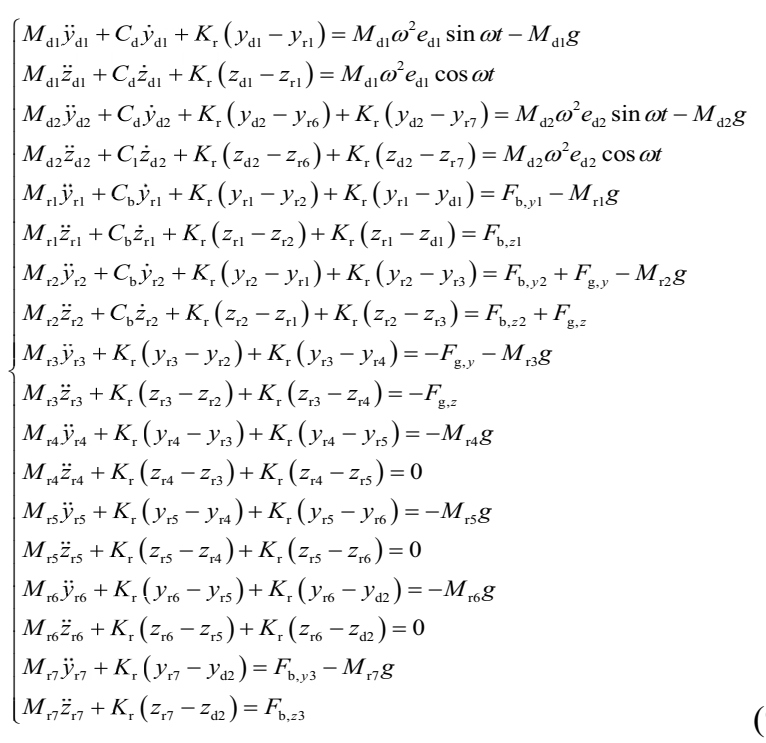


where $\mathrm{M}_{\mathrm{d} 1}$ and $\mathrm{M}_{\mathrm{d} 2}$ is the mass of Disk 1 and Disk 2, $\mathrm{M}_{\mathrm{r} 1}-\mathrm{M}_{\mathrm{r} 6}$ are the mass of rotor points, $\mathrm{C}_{\mathrm{d}}$ and $\mathrm{C}_{\mathrm{b}}$ are viscous damping factor of disk and ball bearing, $\mathrm{K}_{\mathrm{r}}$ is the stiffness of rotor, $\mathrm{F}_{\mathrm{b}, \mathrm{y}}$ and $\mathrm{F}_{\mathrm{b}, \mathrm{z}}$ are supported forces of ball bearing in the $y$-axis and $\mathrm{z}$-axis directions, $\mathrm{F}_{\mathrm{g}, \mathrm{y}}$ and $\mathrm{F}_{\mathrm{g}, \mathrm{z}}$ are meshing forces in the $y$-axis and $z$-axis directions, $\mathrm{e}_{\mathrm{d} 1}$ and $\mathrm{e}_{\mathrm{d} 2}$ are eccentricity of Disk1 and Disk 2 .

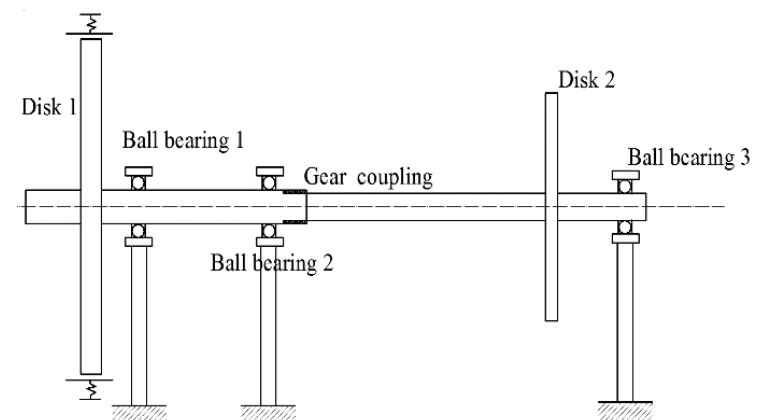

Figure 3. The model of the rotor-bearing system.
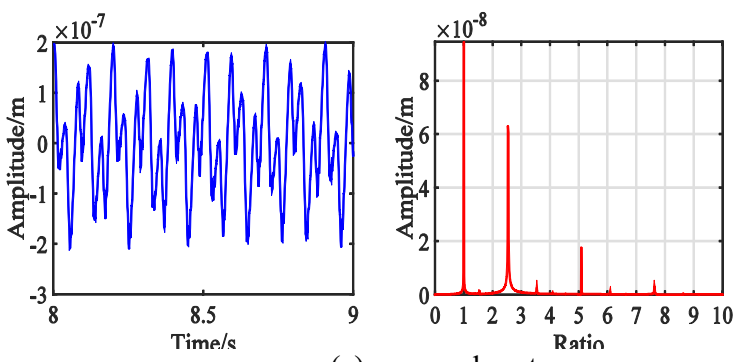

(a) normal system
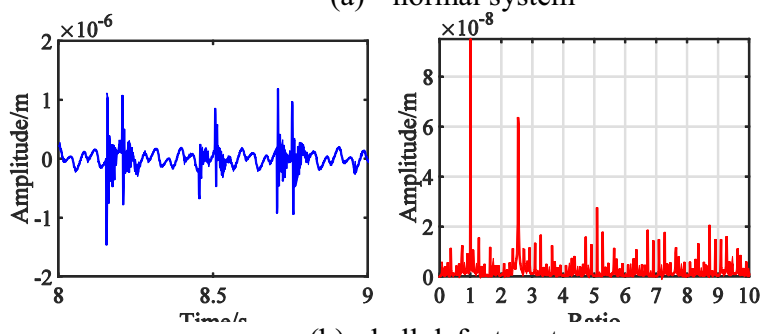

(b) ball defect system

Figure 4. Responses of the rotor when $\omega=600 \mathrm{r} / \mathrm{min}$.
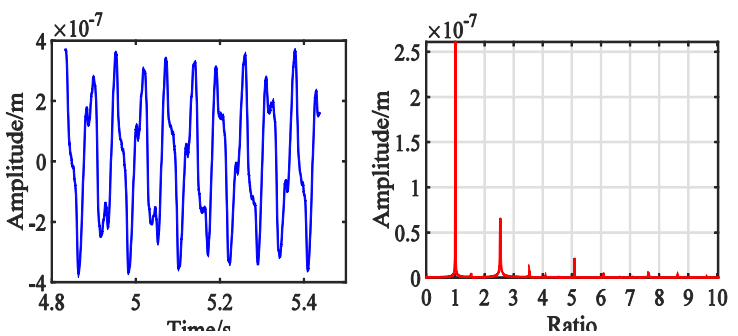

(a) normal system
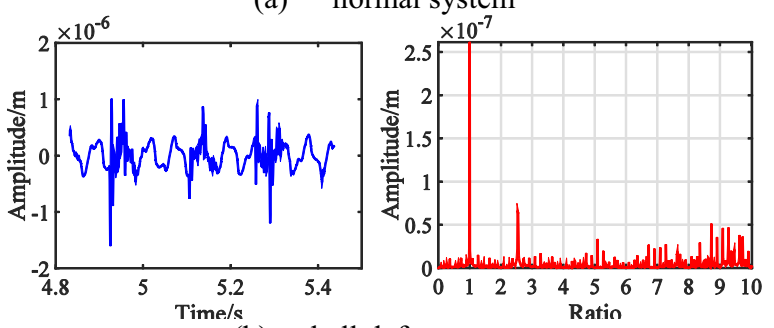

(b) ball defect system

Figure 5. Responses of the rotor when $\omega=600 \mathrm{r} / \mathrm{min}$

\subsection{Results of Simulation}

In this study, the differential equations of motion are solved by the fourth order Runge-Kutta method. The time step of the iterative procedure is $\Delta \mathrm{t}=1 \times 10-5 \mathrm{~s}$. The time varying data corresponding to the first 500 periods generated by the numerical integration is deliberately excluded in order to discard the transient solutions.

Fig. 4 shows the response of a normal system and ball defects on bearing system when $\omega=600 \mathrm{r} / \mathrm{min}$. In Fig. 4(a), it is easy to find the $\mathrm{VC}$ frequency and $2 \mathrm{VC}$ frequency which represents the ball passage frequency, the motion of the rotor is periodic. In Figure 4(b), the time domain signal of the system has great change, the amplitude of vibration has much increase at times and then decreases sharply. In the spectrum, there are sideband frequencies beside VC frequency and its multiple frequencies can be found in the faulted rotor system.

Fig. 5 shows the response of a normal system and ball defects on bearing system when $\omega=1000 \mathrm{r} / \mathrm{min}$. The characteristics of the signal in Figure 5 are similar to it in Fig. 4. With the increasing of speed, the amplitude of high frequency which is caused by ball defects is almost unchanged compared to the increase in fundamental frequency.

\section{Experimental verification}

\subsection{Experimental rotor system}

In this paper, the test facility is built to simulate a compressor rotor system. Fig. 6 shows the overall test setup and the details of the ball bearing.

As discussed in Fig. 6 system component in the test rig is the same. The AC motor is used to drive the rotor and the rotating speed is controlled by a programmable logic controller. Accelerometers and Eddy current sensors are distributed to the experiment bench to get the displacement signal and acceleration signal.

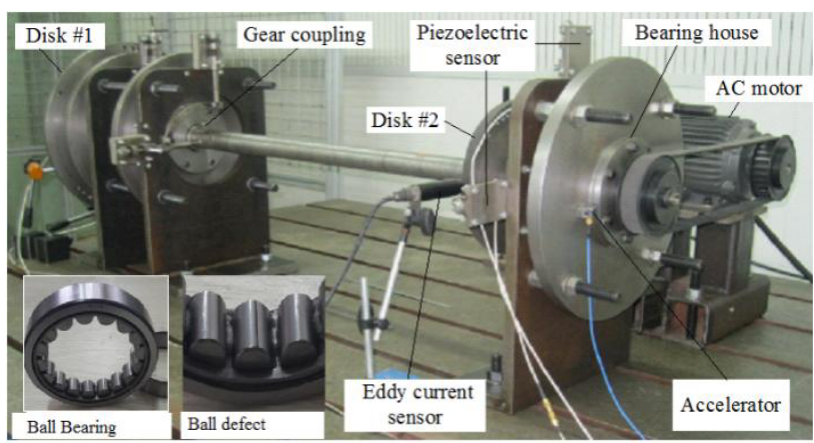

Figure 6. Experimental rotor system.

Table 1. Parameters of the NSK NU211EW bearing

\begin{tabular}{llllll}
\hline \multicolumn{2}{l}{ Size $(\mathrm{mm})$} & & & & $\begin{array}{c}\text { Number } \\
\text { of ball }\end{array}$ \\
\hline $\mathrm{D}_{\mathrm{i}}$ & $\mathrm{D}_{\mathrm{o}}$ & $\mathrm{H}$ & $\mathrm{D}_{\mathrm{w}}$ & $\mathrm{b}_{\mathrm{r}}$ & 17 \\
\hline 55 & 100 & 21 & 78 & 12 & 17 \\
\hline
\end{tabular}

The NSK NU211EW bearings are used on the rotor test. The parameters of bearing are shown in Table 1 . In 
order to simulate the ball bearing fault, a groove is on the surface of ball by electrical discharge machining, which is shown in Fig. 5.

\subsection{Results of Experiment}

Fig. 7 shows the Displacement signal and Acceleration signal of rotor system with ball defects when $\omega=600$ $\mathrm{r} / \mathrm{min}$, and Figure 8 shows the responses of the system at $1000 \mathrm{r} / \mathrm{min}$. From Figure 7(a), the motion of the rotor is periodic and the energy of frequency is focused on the low frequency which between 0 to the fundamental frequency. From Figure 8(a), the largest frequency is between 0 to the fundamental frequency and a frequency appears between fundamental frequency to $2 *$ fundamental frequency. The characteristic of ball defects is not easy to find from figures. After analysis, it is found that, the displacement signal of experiment is not suitable to study the ball defect faults. Therefore the acceleration signal is selected to study the fault characteristic.

From Fig. 7(b), it can be found that the signal of the bearing fault performs as impacts in the high frequency range without any patterns, from Figure 8 (b), it can be found that the amplitude of signal increase obviously and the energy of frequencies moves to high frequency. The characteristics are seemed to the simulation results.
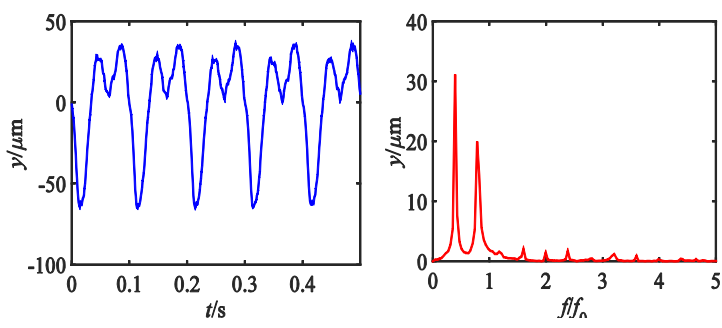

(a)Displacement signal
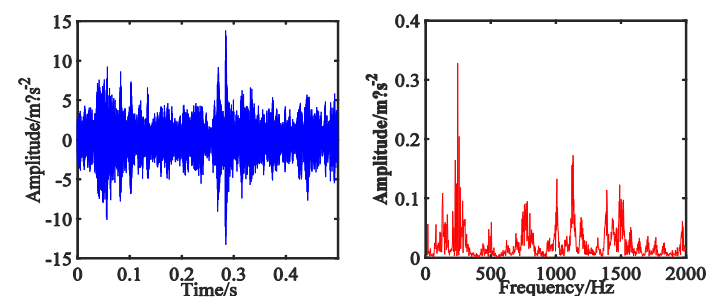

(b)Acceleration signal

Figure 7. Responses of the rotor with ball defects when $\omega=600$ $\mathrm{r} / \mathrm{min}$
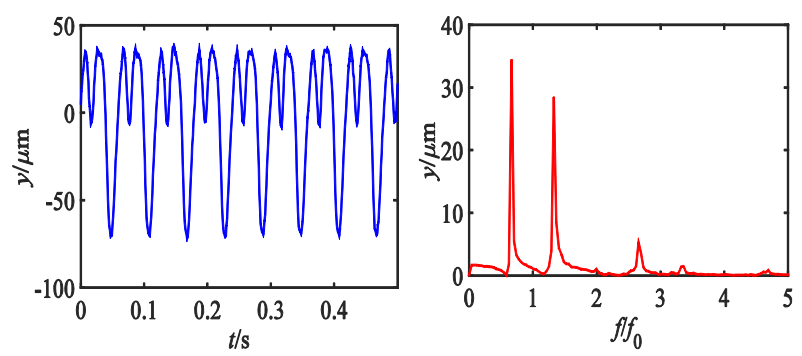

(a)Displacement signal
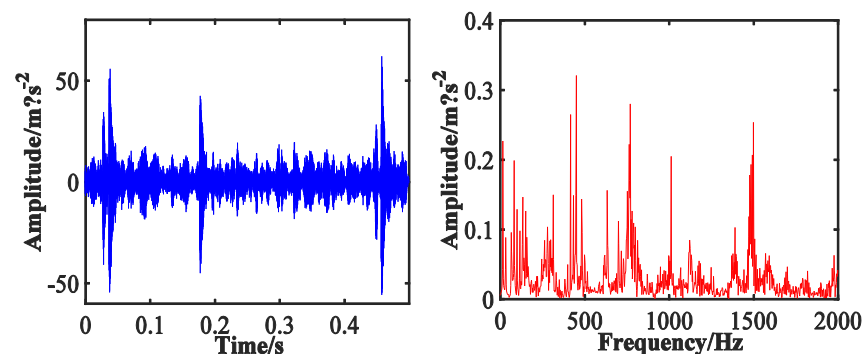

(b)Acceleration signal

Figure 8. Responses of the rotor with ball defects when $\omega=1000$ $\mathrm{r} / \mathrm{min}$

\section{Conclusion}

In this paper, a two-rotor-bearing-gear coupling system model with ball defects on ball bearing to study the characteristics of ball defects of ball bearing. A test facility is built to verify the simulation results. After simulation and experimental analysis, some conclusions are obtained:

1) For the rotor system with the inner race defects on ball bearing, it is found that there is significant change on the dynamic characteristics of the rotor. According to the spectrum diagram of rotor system, there are all kinds of frequency especially high frequency appears under the ball bearing faults.

2) From the results of experiment, it is found that the characteristics of ball defects are not obvious on displacement signal, but acceleration signal reflects the characteristics of ball defects.

The results show the dynamic characteristics of ball defects on the two rotors system. It can help analyze the stability of the system and the fault characteristic of ball bearing.

\section{Acknowledgement}

We are grateful to the Specialized Research Fund for the Doctoral Program of Higher Education (20130032130005)for providing financial support for this work

\section{References}

1. P. K Kankar, Satish C Sharma, S. P Harsha, "Vibrationbasedperformancepredictionof ball bearings caused by localized defects". Nonlinear Dynamics. vol.3 no.69,pp: 847-875, 2012.

2. B Raison, G Rostaing, O.Butscher, and C. S Maroni, "Investigations of Algorithms for Bearing Fault Detection in Induction Drives,'IECON02, pp. 1696-1701 2002,.

3. Poornima V D, Adinarayana S, Rao B V A. Two plane balancing of a conical rotor driven by vertical belt system designed to reduce gyro effect[J]. International Journal of Mechanical Engineering and Robotics Research, 2012, 1.

4. B. Chanqing, Q. Xu, "Dynamic model of ball bearings with internal clearance and waviness". 
Journal of Sound and Vibration. vol.294 pp:23-48, 2006,

6. B Raison, G Rostaing, O.Butscher, and C. S Maroni, "Investigations of Algorithms for Bearing Fault Detection in Induction Drives,'IECON02, pp. 1696-1701 2002,.

7. McFadden, P.D., Smith, J.D, "The vibration produced by multiple points defects of a rolling bearing" vol.98 pp:263-275, 1985

8. Lynagh N, Rahnejat H, Ebrahimi M, et al. Bearing induced vibration in precision high speed routing
5. McFadden, P.D., Smith, J.D, "The vibration produced by multiple points defects of a rolling element bearing " vol.98 pp:263-275, 1985

spindles[J]. International Journal of Machine Tools and Manufacture, 2000, 40(4): 561-577.

9. Eren L, Devaney M J. Bearing damage detection via wavelet packet decomposition of the stator current[J]. Instrumentation and Measurement, IEEE Transactions on, 2004, 53(2): 431-436.

10. G. Zhao, Z. Liu, F. Chen, Meshing force of misaligned spline coupling and the influence on rotor system, International Journal of Rotating Machinery, 2008 (2008) 